\title{
Photosynthesis and Inorganic Carbon Uptake by Spheroplasts Isolated from the Cyanobacterium Anabaena variabilis
}

\author{
By DRORA ZENVIRTH AND AARON KAPLAN* \\ Department of Botany, The Hebrew University of Jerusalem, Jerusalem 91904, Israel
}

(Received 5 January 1984; revised 27 February 1984)

\begin{abstract}
Spheroplasts were prepared from the filamentous cyanobacterium Anabaena variabilis by lysozyme treatment followed by mild sonication. The rate of photosynthesis and the initial rate of accumulation of inorganic carbon within the spheroplasts were very close to those observed in intact cells. The steady-state intracellular inorganic carbon pool, however, was smaller in spheroplasts than in intact cells. It is suggested that the cell wall does not play an essential role in the process of $\mathrm{HCO}_{3}^{-}$transport (leading to accumulation of inorganic carbon internally) but may have a significant impact on the diffusional dissipation of the intracellular pool of inorganic carbon.
\end{abstract}

\section{INTRODUCTION}

The rate of photosynthesis in Anabaena at limiting concentrations of inorganic carbon $\left(\mathrm{C}_{\text {in }}\right)$ in the medium is strongly affected by the rate of $\mathrm{HCO}_{3}^{-}$transport (Kaplan et al., 1980). Studies of the kinetics and mechanism of $\mathrm{HCO}_{3}^{-}$transport, however, are complicated by the presence of the cell wall and the unstirred layer surrounding it. Spheroplasts isolated from these cells may be used for studies of factors limiting the rate of photosynthesis, including $\mathrm{HCO}_{3}^{-}$transport, provided that the spheroplasts are capable of a high rate of photosynthesis. In the present communication, the photosynthetic and $\mathrm{C}_{\text {in }}$ transport capabilities of spheroplasts isolated from Anabaena variabilis are compared with those observed in intact cells.

\section{METHODS}

Anabaena variabilis strain M-3 from the collection of Tokyo University was grown as described by Kaplan et al. (1980). Spheroplasts were prepared by suspending the cells in $10 \mathrm{mM}-\mathrm{MES}, 0.5 \mathrm{M}$-sucrose, $10 \mathrm{mM}-\mathrm{MgCl}_{2}, 5 \mathrm{mM}$ potassium-sodium phosphate, $2 \%(\mathrm{w} / \mathrm{v}) \mathrm{BSA}, \mathrm{pH} 6.9$ and $1 \mathrm{mg}$ lysozyme $\mathrm{ml}^{-1}$ for $1 \mathrm{~h}$, at $32{ }^{\circ} \mathrm{C}$, as described by Spiller (1980). The lysozyme digestion was followed by mild sonication for $3 \mathrm{~min}$ in a bath sonicator at low energy, followed by centrifugation $(100 \mathrm{~g}, 5 \mathrm{~min})$. The pellet was resuspended in the same medium containing $0.5 \% \mathrm{BSA}$, and kept on ice. The spheroplast suspension was diluted $1: 10$ with $20 \mathrm{mM}-\mathrm{HEPES}, 0.4 \mathrm{M}-\mathrm{mannitol}, 10 \mathrm{mM}-\mathrm{MgCl}_{2}$,

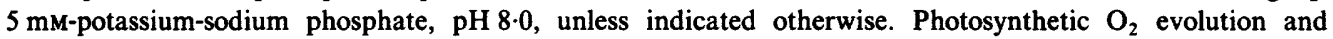
intracellular $\mathrm{C}_{\mathrm{in}}$ concentration were determined using an $\mathrm{O}_{2}$ electrode and the filtering centrifugation technique, respectively (Kaplan et al., 1980), except that spheroplasts were centrifuged through a mixture of 1,6-bis(2ethylhexyl)phthalate and dibutyl phthalate instead of silicone oil.

\section{RESULTS AND DISCUSSION}

Treatment of the filamentous cyanobacterium $A$. variabilis with lysozyme resulted in the formation of spheroplasts. Mild sonication was required to release the spheroplasts from the cell wall residues (not shown).

Spheroplasts were very sensitive to the osmotic concentration in the medium. Exposure to mannitol concentrations lower than $0.3 \mathrm{M}$ resulted in lysis of spheroplasts, as indicated by the

Abbreviation: $\mathrm{C}_{\mathrm{in}}$, inorganic carbon. 


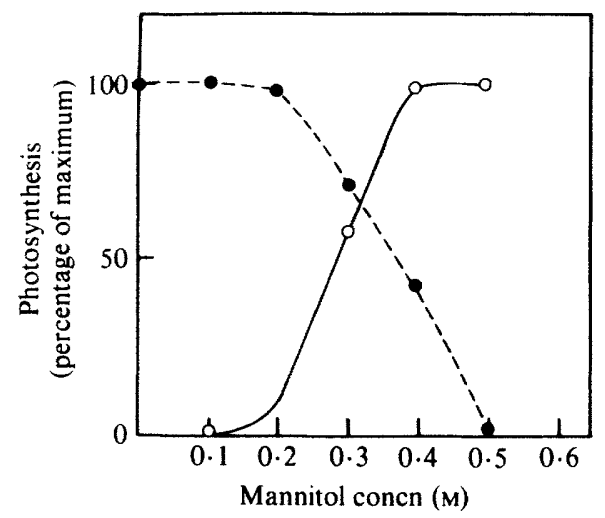

Fig. 1. Dependence on mannitol concentration in the medium of photosynthetic rate of intact cells (O) and spheroplasts $(O)$ isolated from $A$. variabilis. A value of $100 \%$ corresponds to the maximal photosynthetic rate depicted in Fig. 2. Experiments were done at $30^{\circ} \mathrm{C}, 7 \mathrm{~mW} \mathrm{~cm}{ }^{-2}(400-700 \mathrm{~nm})$, and in the presence of $0.5 \mathrm{~mm}-\mathrm{NaHCO}_{3}$ and $0.5 \mathrm{~mm}$-sodium-potassium phosphate.

appearance of phycobilins in the medium (not shown) and the loss of photosynthetic activity (Fig. 1). Intact cells were also very sensitive to osmotic concentration, but maximal photosynthetic activity was observed below $0.2 \mathrm{M}$-mannitol. The inflexion point (Fig. 1) was somewhat variable and presumably reflected the osmotic concentration within the cells. The different behaviour of spheroplasts and intact cells with respect to osmotic concentration, osmotic adjustment and possible role of turgor are now being investigated. The experiments reported below were carried out in the presence of $0.4 \mathrm{M}$-mannitol in the spheroplast medium or in its absence in the case of intact cells.

The photosynthetic response of spheroplasts to the concentration of $\mathrm{C}_{\text {in }}$ in the medium was very similar to that found in intact cells (Fig. 2), the maximal photosynthetic rate being somewhat higher in the latter. The dependence of photosynthesis on temperature and light intensity was also not appreciably affected following the formation of spheroplasts [not shown, but data very similar to those of Collins \& Boylen (1982) in intact cells]. It is concluded that spheroplasts isolated by the technique described here exhibit photosynthetic capability similar to that found in intact cells and can thus be used to study factors limiting maximal photosynthetic rate.

The rate of photosynthesis in intact $A$. variabilis cells, at limiting $\mathrm{C}_{\mathrm{in}}$ concentration, is determined by the $C_{\text {in }}$ transporting capability (Kaplan et al., 1980; Marcus et al., 1982). The finding that spheroplasts exhibited similar rates of photosynthesis as intact cells at limiting levels of $\mathrm{C}_{\text {in }}$ (Fig. 2) suggests that $\mathrm{C}_{\text {in }}$ transporting capability was not altered following the formation of spheroplasts. Figure 3 shows the time course of accumulation of $\mathrm{C}_{i n}$, following the supply of $\mathrm{HCO}_{3}^{-}$to intact cells and spheroplasts. While the initial rate of accumulation of $\mathrm{C}_{\text {in }}$ was similar, the steady-state level of intracellular $C_{\text {in }}$ achieved was about three times higher in intact cells. The steady-state $C_{i n}$ pool reflects the rates of influx and dissipation. The latter is a result of photosynthetic utilization and efflux. Photosynthetic utilization of the intracellular $C_{\text {in }}$ appears to be similar to that of intact cells (Fig. 2). Thus it is possible that, in the absence of cell wall, efflux of inorganic carbon is larger, resulting in the lower steady-state intracellular $\mathrm{C}_{\text {in }}$ pool in spheroplasts. The normal photosynthetic rate in spheroplasts with a decreased $C_{i n}$ pool may be explained by the finding that the intracellular level of $\mathrm{C}_{\text {in }}$ in spheroplasts almost saturated the photosynthetic rate in whole cells (Kaplan et al., 1980).

The rate of photosynthesis (Fig. 2) was several times higher than the expected, uncatalysed rate of conversion of intracellular $\mathrm{HCO}_{3}^{-}$to $\mathrm{CO}_{2}$ (the substrate of ribulose-1,5-bisphosphate carboxylase). This was particularly pronounced in the case of spheroplasts where the intracellular $\mathrm{C}_{\text {in }}$ pool was lower than in intact cells (Fig. 3). Carbonic anhydrase activity could not be detected in $A$. variabilis. Possibly, very low carbonic anhydrase activity is associated with 


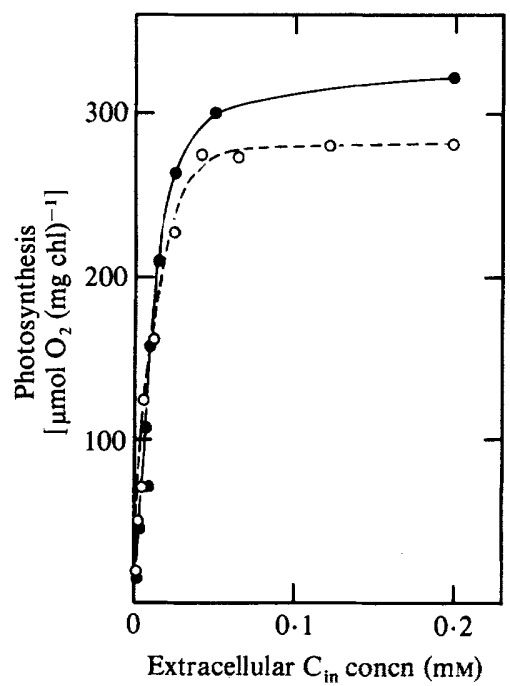

Fig. 2.

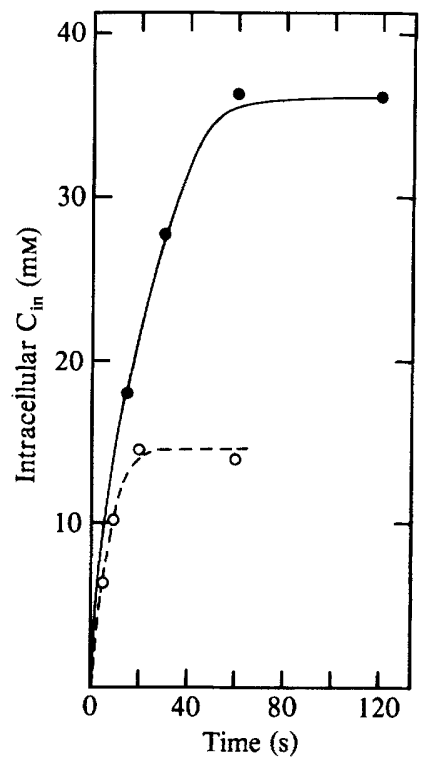

Fig. 3

Fig. 2. Photosynthetic response to $C_{i n}$ concentration in the medium of intact cells (O) and spheroplasts (O) isolated from $A$. variabilis. Experimental conditions were as in Fig. 1.

Fig. 3. Accumulation of $\mathrm{C}_{\mathrm{in}}$ within cells $(O)$ and spheroplasts $(\mathrm{O})$ isolated from $A$. variabilis. Experimental conditions were as in Fig. 1, except that sodium-potassium phosphate was omitted.

the carboxysomes, enabling faster conversion of $\mathrm{HCO}_{3}^{-}$to $\mathrm{CO}_{2}$ close to the site of its consumption.

It is concluded that spheroplasts isolated by the technique described here exhibit photosynthetic capability similar to that of intact cells. The lack of the cell wall minimizes diffusional limitations and makes these spheroplasts suitable for studies of transport of nutrients, including $\mathrm{C}_{\mathrm{in}}$, as well as factors limiting maximal photosynthetic rate.

This research was supported by a grant from the United States-Israel Binational Science Foundation (BSF), Jerusalem, Israel.

\section{REFERENCES}

Collins, C. D. \& Boylen, C. W. (1982). Physiological responses of Anabaena variabilis (Cyanophyceae) to instantaneous exposure to various combinations of light intensity and temperature. Journal of Phycology 18, 206-211.

Kaplan, A., BADger, M. R. \& BerRy, J. A. (1980). Photosynthesis and the intracellular inorganic carbon pool in the bluegreen alga Anabaena variabilis: response to external $\mathrm{CO}_{2}$ concentration. Planta 149 , 219-226.
Marcus, Y., Zenvirth, D., Harel, E. \& Kaplan, A. (1982). Induction of $\mathrm{HCO}_{3}^{-}$transporting capability and high photosynthetic affinity to carbon dioxide by low concentration of $\mathrm{CO}_{2}$ in Anabaena variabilis. Plant Physiology 69, 1008-1012.

SPILLER, H. (1980). Photophosphorylation capacity of stable spheroplast preparation of Anabaena. Plant Physiology 66, 446-450. 